\title{
M-Learning for Elderlies: A Case Study
}

Fernando de la Prieta, Antonia Macarro, Amparo Jiménez, Amparo Casado, Kasper Hallenborg, Juan F. De Paz, Sara Rodríguez, and Javier Bajo

\begin{abstract}
In this article a case study about m-learning for elderlies using mobile devices is presented. The study focuses on a practical study about language learning for elderly students that attend classes in the so-called Inter-university program for Elderly People. The recent surge of university programs for elderly people requires novel solutions related to learning methods, directed by the special needs of this sector of the society.
\end{abstract}

Keywords: elderlies, m-learning, mobile devices, disabled people.

\section{Introduction}

There is an ever growing need to supply constant care and support to the disabled and elderly and the drive to find more effective ways to provide such care has become a major challenge for the scientific community [3]. During the last three decades the number of Europeans over 60 years old has risen by about $50 \%$. Today they represent more than $25 \%$ of the population and it is estimated that in 20 years this percentage will rise to one third of the population, meaning 100 millions of citizens [3]. In the USA, people over 65 years old are the fastest growing segment of the population [1] and it is expected that in 2020 they will represent about 1 of 6 citizens totaling 69 million by 2030. Furthermore, over $20 \%$

Fernando de la Prieta $\cdot$ Juan F. De Paz $\cdot$ Sara Rodríguez

Computer and Automation Department, University of Salamanca, Salamanca, Spain

e-mail: $\{$ fer, fcofds, sgr $\}$ @usal.es

Antonia Macarro · Amparo Jiménez · Amparo Casado · Javier Bajo

Universidad Pontificia de Salamanca, Spain

e-mail: \{mamacarroal, ajimenezvi, acasadome, jbajope\} @upsa.es

Kasper Hallenborg

University of Shouthern Denmark, Denmark

e-mail: hallenborg@mmmi.sdu.dk

S. Omatu et al. (Eds.): Distributed Computing and Artificial Intelligence, AISC 151, pp. 637-645. springerlink.com

(C) Springer-Verlag Berlin Heidelberg 2012 
of people over 85 years old have a limited capacity for independent living, requiring continuous monitoring and daily care [2]. Some estimations of the World Health Organization show that in 2025 there will be more than 1000 million people aged over 60 in the world, so if this trend continues, by 2050 will be double, with about the $80 \%$ concentrated in developed countries [6].

Education is the cornerstone of any society and it is the base of most of the values and characteristics of that society. The new knowledge society offers significant opportunities for AmI applications, especially in the fields of education and learning [5]. The new communication technologies propose a new paradigm focused on integrating learning techniques based on active learning (learning by doing things, exchange of information with other users and the sharing of resources), with techniques based on passive learning (learning by seeing and hearing, Montessori, etc.) [4]. While the traditional paradigm, based on a model focused on face to face education, sets as fundamental teaching method the role of the teachers and their knowledge, the paradigm based on a learning model highlights the role of the students. In this second paradigm the students play an active role, and build, according to a personalized action plan, their own knowledge. Moreover, they can establish their own work rhythm and style. The active methodology proposes learning with all senses (sight, hearing, touch, smell and taste), learn through all possible methods (school, networking, etc.), and have access to knowledge without space or time restrictions (anywhere and at any time).

There are different studies that have used the Ambient Intelligence to facilitate learning. In [3], Bomsdorf shows the need to adapt intelligent environments to changes depending on the educational context and the characteristics of users. Morkenet al. [6] analyze the characteristics of intelligent environments for learning. They focus on the role of mobility in educational environments and the role that acquire the mobile devices. Naismith et al. [7] conducted a detailed study describing the role of mobile devices in education, analyzing the characteristics of the devices and their capacity for learning in educational environments. All these approaches are focused on the role of learning in Ambient Intelligence environments, but none of them is oriented on learning for dependents or elderly people. The following section presents a multiagent architecture that facilitates learning methodology using an active through mobile devices.

This work presents a practical study about language learning for elderly students that attend classes in the so-called Inter-university program for Elderly People at the Pontifical University of Salamanca, Spain. The recent surge of university programs for elderly people requires novel solutions related to learning methods, directed by the special needs of this sector of the society. With the aim of obtaining an improvement in the French language learning, we have tested different methodologies. The one presented in this paper is an empirical one, based on the M-learning paradigm. This paper focuses in the combination of the new information technologies along with the traditional teaching. In this way it 
will be possible to combine the advantages of the face to face teaching with the advantages of distance learning. It will be necessary to upgrade the systems of evaluation/accreditation to assess the knowledge or skills acquired during the learning process. To achieve this objective, we propose the use of mobile devices, intelligent systems and wireless communications. The aim is to provide complementary methods to the traditional learning strategies. The proposed mechanism was tested in a case study, trying to evaluate the impact of the new approach on the elderly students.

The rest of the paper is structured as follows: Next section introduces the problem that motivates most of this research. Section 3 describes a case study to test the proposal and, finally, Section 4 shows the results and the conclusions obtained.

\section{Background}

This section presents the problem that motivates this research. More specifically, we will focus in two main concepts: Learning techniques oriented to elderly people and mobile learning techniques. In the following paragraphs we revise the related work about these two concepts.

\subsection{Learning Techniques Oriented to Elderly People}

Elderly student are acquiring a relevant role in Spanish universities. Different factors as the improvement in the quality of life and the educational interests of this sector of the population contribute to these new educational needs. In 1973, professor Pierre Vellas created the first university program for elderlies in Toulouse. Since then, the growth of these university programs has been unstoppable, and now they exist in practically all the continents. Focusing on Spain, the University of Alcalá de Henares and the Pontifical University of Salamanca were the first university in including a university program for elderlies in 1993. These educational programs presented a new challenge regarding learning methods adapted to the special needs of the new students. These students present a series of special characteristics: They usually compose a heterogeneous group, with different academic background (we can find students with basic education and students with university degrees), different ages (it can vary from 55 to 80 years), and different level of language domain. In Spain, most of these people studied a foreign language, French in most of the cases, but most of them don't have memories about this language. In general they are students that attend the classes and are interested in continuing with the students in the subsequent years.

Apart from the special characteristics of this new student profile, there is another obstacle: there not exists a didactic method oriented to elderly students. 
All the existing methods are oriented to children, teenagers or young people. It has only been possible to find an English method oriented to elderlies [10]. The existing learning methods are not appropriated for the special characteristics of these new students. Thus, it is necessary to investigate in new learning techniques and methods oriented to satisfy the special requirements of this social sector.

\subsection{Mobile Learning Techniques}

The experience acquired after teaching French during a decade to elderly students, it is possible to conclude that the new information and communication technologies (ICT) are still a challenge for these students. The impact and growing use of the ICTs in our society it is a reality and it is not possible to live without them. The use of the ICTs can help to notably improve the quality of life of elderlies and facilitate their integration in the information society. The advances in ICTs in this century are very important, and in parallel, the traditional educational model has been substituted for new paradigms that incorporate e-learning methods. One of the advantages of these methods is the elimination of temporal and location barriers. There are different types of e-learning methods. It is possible to distinguish:

- E-learning is electronic learning, and makes use of communication networks as Internet or Intranets and platforms as Moodle, specialized in tele-learning.

- B-learning or blended learning is a combination of traditional teaching and electronic learning (E-learning). It combines attendance modules and non-attendance modules.

- M-learning or mobile learning represents a step ahead in educational models. It adapts the learning methods to mobile devices such as mobile phones, PDAs, tablets, pocket pcs, i-pads, etc. An specialization of mlearning is MALL (Mobile assisted language learning), focused on language learning from mobile devices [11].

In this paper we focus on M-learning, and more specifically in MALL. Klopfer 10 indicates that the mobile devices should incorporate five characteristics to be appropriated for mobile learning: portability, social interactivity, contextawareness, connectivity and individuality. M-learning can be combined with traditional learning methods. It is necessary to remark that M-learning is a ubiquitous method and avoids temporal and location restrictions. Moreover, Mlearning becomes more important as the mobile devices become more important. According to a study of ITAD consulting, for the year 2015, the mobile Internet penetration worldwide will reach 37\%. According Soichi Nakajima [12] the mobile Internet has reached a final take-off stage in Western Europe and North America, so far only been seen in Japan for almost a decade and to a lesser extent, South Korea. This growth in the number of smartphones has a big impact in the 
information society, and most of the users are now replacing the typical mobile phone. Besides applications for mobile phones makes smartphones much more attractive to users and also be the way to make more mobile connections [16]. The World Summit Award Mobile Content (WSA-mobile), is a global initiative of the European Academy of Digital Media - EADiM to select and promote contents and creativity in websites [14]. The project MOBIlearnof the European Comission join together universities and telecommunications companies from Europe, Israel, USA and Australia, with the aim of defining theoretical models for learning process carried out by means of mobile technologies. The Learning and Skills Network (LSN) organization promotes MoLeNET (Mobile Learning Network) to design educational products based on mobile devices [13]. In Spain, the University RoviraiVirgilicreated apodcasting Project to improve language learning [8]. Lingling Yang remarks the importance of language learning through mobile devices [8]. In [15], Jan Herrington describes a case study in australian universities to learn using smartphones and iPods.

There are different studies that have used the Ambient Intelligence to facilitate learning. In [4], Bomsdorf shows the need to adapt intelligent environments to changes depending on the educational context and the characteristics of users. Naismith et al. [18] conducted a detailed study describing the role of mobile devices in education, analyzing the characteristics of the devices and their capacity for learning in educational environments. All these approaches are focused on the role of learning in Ambient Intelligence environments, but none of them is oriented on learning for dependents or elderly people. The following section presents a case study to evaluate a learning methodology using an active through mobile devices.

\section{Case Study: University Program Oriented to Elderlies}

This study has two objectives: i) To improve language learning in university programs oriented to elderlies, and ii) to contribute to integrate the elderly people in the information society, making use of the information technologies. At present there are various tools to facilitate the active learning, such as forums, wikis, email, chat, virtual campuses, and so on. However, none of them is focused to language learning for elderly people. This paper presents an interactive system specifically designed for language learning for elderly people and people with visual disabilities. The proposed approach includes new interaction techniques adapted to be applied in mobile devices. Interaction techniques have been used to design Ambient Intelligence interaction mechanisms suitable for use in teaching languages to people involved in courses at the university program for elderlies. Therefore, interfaces have been made simple and straightforward and have facilitated interaction through touch devices. The application developed for mobile devices contain a series of tests that individuals can complete to carry out language learning. Thus, the student uses a type of interface that allows him to interact with the system. 
After revising the related work, it has been observed that the existing approaches are oriented to language learning for young students. Young students use mobile devices in their daily life, and it has not been possible to find any project oriented to people up to 55 years. In this sense, the approach presented in this paper proposes an innovative perspective where the students are elderlies.

The application is based on a navigation menu using the accelerometer available in many mobile devices, especially in the iPhone platform. This application may solve the problems that elderlies have while using a menu with different options. Cutting-edge devices have touch screens and it's impossible for them to identify where they are pressing. A movement recognition algorithm has been created in order to collect all data necessary for the successful operation of the system [19].

\section{Results}

To evaluate the proposed approach, the system was tested with two different groups of students at the university program for elderlies at the Pontifical University of Salamanca, Spain. The tests consisted of 2 tests for two different groups, one performed in Group 1 and another made to Group 2. The first test involved 12 individuals, while the second test involved 15 individuals. The sex of individuals was not taken into consideration to perform this test, because this parameter has not been considered as significant for this study. Each of the individuals completed one of the tests proposed in the mobile application, and noted by 10 questions. After the test, each individual completed a form on which he was asked about the evaluation of the test. The test assessed 5 items:

- Usefulness of the test. This item is valued feedback from users about the usefulness of the test as a learning tool.

- Easy to use mobile phone. This item assesses the usability of the proposed application.

- Utility as a tool for teaching languages. This item is valued feedback from users about the usefulness of the tool for language learning.

- Using mobile phone before for similar activities. This item is valued the ease and frequency of use of mobile devices.

- Overall assessment of the test. This item assesses the overall opinion about the test users. 
The results obtained in the experiment are show in the following table:

Table 5 Results for the items.

\begin{tabular}{|c|c|c|c|}
\hline & G1 & $\mathrm{G} 2$ & $\mathrm{G} 1+\mathrm{G} 2$ \\
\hline \multicolumn{4}{|c|}{ Utility of the test } \\
\hline Very Useful & $75 \%$ & $60 \%$ & $55,55 \%$ \\
\hline Quite Useful & $0 \%$ & $40 \%$ & $33,33 \%$ \\
\hline Useful & $25 \%$ & $0 \%$ & $11,11 \%$ \\
\hline Not very useful & $0 \%$ & $0 \%$ & $0 \%$ \\
\hline Not useful & $0 \%$ & $0 \%$ & $0 \%$ \\
\hline \multicolumn{4}{|c|}{ Easy to use mobile phone } \\
\hline Very Easy & $50 \%$ & $20 \%$ & $11,11 \%$ \\
\hline Easy & $0 \%$ & $60 \%$ & $55,55 \%$ \\
\hline Normal & $50 \%$ & $0 \%$ & $22,22 \%$ \\
\hline Difficult & $0 \%$ & $0 \%$ & $0 \%$ \\
\hline Very difficult & $0 \%$ & $25 \%$ & $11,11 \%$ \\
\hline \multicolumn{4}{|c|}{ Utility of the approach as a tool for language learning } \\
\hline Very appropriated & $25 \%$ & $20 \%$ & $33,33 \%$ \\
\hline Quite appropriated & $0 \%$ & $20 \%$ & $11,11 \%$ \\
\hline Appropriated & $75 \%$ & $0 \%$ & $0 \%$ \\
\hline Not Very appropriated & $0 \%$ & $20 \%$ & $11,11 \%$ \\
\hline Inappropriate & $0 \%$ & $40 \%$ & $22,22 \%$ \\
\hline \multicolumn{4}{|c|}{ Previous use of the mobile phone for similar activities } \\
\hline Yes & $100 \%$ & $80 \%$ & $88,88 \%$ \\
\hline No & $0 \%$ & $0 \%$ & $0 \%$ \\
\hline Not answer & $0 \%$ & $20 \%$ & $12,12 \%$ \\
\hline \multicolumn{4}{|c|}{ Global evaluation of the test } \\
\hline Very satisfied & $25 \%$ & $40 \%$ & $33,33 \%$ \\
\hline Quite satisfied & $25 \%$ & $60 \%$ & $44,44 \%$ \\
\hline Satisfied & $50 \%$ & $0 \%$ & $22,22 \%$ \\
\hline Not Very satisfied & $0 \%$ & $0 \%$ & $0 \%$ \\
\hline Unsatisfied & $0 \%$ & $0 \%$ & $0 \%$ \\
\hline
\end{tabular}

Taking into account these results, it is possible to conclude that the approach is promising and can be of interest for this sector of the population. The participants in this experiment provided some feedback about the proposed approach: they indicated that the approach is very interesting for certain aspects, as verbs learning, and it is innovative, since it is not useful for them the use of mobile devices in the classes. Some of them also indicated that it would be of interest to improve the proposed approach with accessibility facilities, specifically to augment the size of the fonts.

Acknowledgements. This work has been supported by the Junta de Castilla y León project PON147A11-2. 


\section{References}

1. Anastasopoulos, M., Niebuhr, D., Bartelt, C., Koch, J., Rausch, A.: Towards a Reference Middleware Architecture for Ambient Intelligence Systems. In: ACM Conference on Object-Oriented Programming, Systems, Languages, and Applications (2005)

2. Angulo, C., Tellez, R.: Distributed Intelligence for smart home appliances. Tendencias de la minería de datos en España. Red Española de Minería de Datos. Barcelona, España (2004)

3. Bajo, J., Corchado, J.M., de Paz, Y., de Paz, J.F., Rodríguez, S., Martín, A., Abraham, A.: SHOMAS: Intelligent Guidance and Suggestions in Shopping Centres. Applied Soft Computing 9(2), 851-862 (2009)

4. Bomsdorf, B.: Adaptation of Learning Spaces: Supporting Ubiquitous Learning in Higher Distance Education. In: Davies, N., Kirste, T., Schumann, H. (eds.) Dagstuhl Seminar Proceedings. Mobile Computing and Ambient Intelligence: The Challenge of Multimedia, Dagstuhl, Germany (2005)

5. Brown, T.H.: Beyond constructivism: Exploring future learning paradigms. In: Education Today, issue 2 of 2005. Aries Publishing Company, Thames (2005)

6. Friedewald, M., Da Costa, O.: Science and Technology Roadmapping: Ambient Intelligence in Everyday Life (AmI@Life). Working Paper. Seville: Institute for Prospective Technology Studies IPTS (2003)

7. Kurniawan, S.H., King, A., Evans, D.G., Blenkhorn, P.L.: Personalising web page presentation for older people. Interacting with Computers 18, 457-477 (2006)

8. Naismith, L., Lonsdale, P., Vavoula, G., Sharples, M.: Futurelab Literature Review in Mobile Technologies and Learning, Technical Report for Futurelab (2004), http://www. futurelab.org.uk/research/reviews/reviews_11_an d12/11_01.htm

9. Martí, C., Mar, González, E., Vanessa, Cervera, G., Mercè: Speak new words, speak new languages: a podcasting experience in multicultural settings

10. Revista MASTER NEW MEDIA; 17 de enero de (2006), http: / /www.masternewmedia.org/es/2006/01/17/aprendizaje_mo vil_mlearning_es_lo.htm

11. Klopfer, E., Squire, K., Jenkins, H.: Environmental Detectives: PDAs as a window into a virtual simulated world. In: Proceedings of IEEE International. Workshop on Wireless and Mobile Technologies in Education. IEEE Computer Society, Vaxjo (2002)

12. Chinnery, G.M.: EMERGING TECHNOLOGIES Going to the MALL: Mobile Assisted Language Learning, vol. 10(1), pp. 9-16. University of Maryland, Baltimore County (2006)

13. Soichi Nakajima 2015. En 2015 el $37 \%$ de la población utilizará internet móvil (2011), http: //congresoweb.es/2011/01/en-2015-el-37-de-lapoblacion-utilizara-internet-movil/

14. Douch, R., Savill-Smith, C., Parker, G., Attewell, J.: Work-based and vocational mobile learning - Making IT work. Learning and Skills Network (2010), http://www.molenet.org.uk/pubs/

15. EADIM, http://www. eadim.com/ 
16. Herrington, J., Herrington, A., Mantei, J., Olney, I., Ferry, B. (eds): New technologies, new pedagogies: Mobile learning in higher education, Faculty of Education, University of Wollongong, p. 138 (2009)

17. Frohberg, D.: Mobile Learning is Coming of Age: What we have and what we still miss. In: Proceedings for DeLFI 2006, September 11-14 (2007)

18. Naismith, L., Lonsdale, P., Vavoula, G., Sharples, M.: Futurelab Literature Review in Mobile Technologies and Learning, Technical Report for Futurelab (2004), http://www. futurelab.org.uk/research/reviews/reviews_11_an d12/11_01.htm

19. Sánchez, A., Villarrubia, G., Macarro, A., Jiménez, A., Zato, C., Bajo, J., Rodríguez, S., Hallenborg, K., Corchado, J.M.: Menu navigation in mobile devices using the accelerometer. In: Proceedings of ISAMI 2011 (in press) 